\title{
Resoluções Visuais de Alguns Problemas de Matemática da Educação Básica
}

\author{
Hilário Alencar ${ }^{1} \quad$ Larissa Cândido ${ }^{2} \quad$ Milena Farias
}

\begin{abstract}
Resumo
Em seu consagrado livro Problem-Solving Through Problems, Loren C. Larson propôs doze estratégias para a resolução de problemas. Inspirados no planejamento recomendado, construímos resoluções de alguns problemas de Matemática, envolvendo álgebra, geometria e trigonometria, que são conhecidos na Educação Básica. Observamos que das estratégias apresentadas, foram utilizadas com maior predominância a segunda, sexta e sétima estratégias, que são, respectivamente, trace uma figura, explore as simetrias e divida em casos. Dessa forma, no decorrer deste artigo, apresentamos o que denominamos de "resolução visual"para uma série de problemas, mediante uma sequência de figuras.
\end{abstract}

Palavras-chave: Resoluções visuais; Educação básica; Álgebra; Geometria; Trigonometria.

\begin{abstract}
In his well-established book Problem-Solving Through Problems, Loren C. Larson proposed twelve problem-solving strategies. Inspired by the recommended planning, we construct resolutions of some Mathematical problems, involving algebra, geometry and trigonometry, that are known in Basic Education. We observed that the second, sixth and seventh strategies, which are, respectively, trace a figure, explore the symmetries and divide in cases, were used with greater predominance. Thus, in the course of this article, we present what we call "visual resolution" for a series of problems, through a sequence of figures.
\end{abstract}

Keywords: Visual resolutions; Basic education; Algebra; Geometry; Trigonometry.

\section{Introdução}

O conjunto de regras e métodos que conduzem à descoberta, à invenção e à resolução de problemas é denominado heurística, do grego heuristiké. Essencialmente, essa palavra significa a arte de encontrar, descobrir. Esse tema é fértil em publicações de textos, artigos, teses e dissertações;

\footnotetext{
${ }^{1}$ Parcialmente apoiado pelo CNPq.

${ }^{2}$ Parcialmente apoiada pelo INCTMat/CNPq.
} 
como por exemplo, [2], [6], [9], [10], [11], [12] e [13].

Neste trabalho consideraremos problema como descrito por A. H. Schoenfeld, ver [12], isto é, uma proposição não resolvida, que constitui um desafio e oferece algum grau de dificuldade para aquele que se propõe a resolvê-la. De fato, Schoenfeld diferencia problema e exercício. Um exercício é uma proposição não resolvida que pode ser solucionada usando procedimentos de rotina, sem que haja a necessidade de raciocínios mais elaborados. Vale observar ainda que uma proposição pode ser um problema para um indivíduo e, ao mesmo tempo, ser um mero exercício para outro. Por exemplo, encontrar o triângulo de área máxima dentre todos os triângulos inscritos em um círculo dado é um problema para aqueles alunos que têm conhecimento apenas de Matemática em termos de Ensino Médio, mas é um exercício de rotina para universitários que conhecem o cálculo e sabem maximizar funções de várias variáveis.

Em Matemática os problemas surgem, ver [9], a partir de:

- Uma questão concreta da realidade envolvendo outras ciências;

- Uma questão proposta após observar exemplos de situações simples que possuem soluções;

- Generalizações de resultados demonstrados em situações diferentes.

Um problema em Matemática deve ter uma clareza no seu enunciado e, além disso, suas hipóteses são completamente essenciais na sua resolução. Ademais, a originalidade e a complexidade cristalina das técnicas envolvidas na solução caracterizam sua importância na Matemática. A tentativa de solucionar um problema conduz ao desenvolvimento intelectual, além de potencializar habilidades como o raciocínio lógico, tenacidade, disciplina, paciência, visão geométrica, entre outras.

A resolução de um problema em Matemática pressupõe um conhecimento científico e é resultado de uma investigação metódica, onde se observam fortemente as suposições postas na questão, isto é, as hipóteses do problema. De fato, um caminho para a descoberta de novos resultados em Matemática requer, em geral, que teorias sejam desenvolvidas na medida em que os conceitos estão sendo introduzidos, uso de resultados já provados, observação de exemplos existentes sobre o problema e determinação de suas propriedades.

Em [6], são listadas doze estratégias para a resolução de problemas. Diferentemente de [9], o autor não lista um roteiro a ser seguido, nem regras gerais sobre como proceder na resolução de problemas matemáticos, mas apresenta as principais estratégias usadas na resolução de problemas. Larson, deixa claro que essa lista não esgota todas as possibilidades de estratégias de um problema, isto é, existirão problemas nos quais as estratégias citadas não poderão ser aplicadas.

No que segue, faremos uma breve descrição de cada uma das doze estratégias.

\section{Procure por um padrão.}

Virtualmente, todos os resolvedores de problemas iniciam sua análise gerando um sentimento sobre o problema, convencendo-se sobre a plausibilidade do resultado. Isso é feito da melhor maneira examinando-se os casos particulares mais imediatos. Quando essa exploração é empreendida de um modo sistemático, os padrões podem emergir e irão inspirar ideias sobre como proceder na resolução do problema.

2. Trace uma figura.

Sempre que possível é útil descrever um problema de forma pictórica, o que pode ser uma figura, um diagrama ou um grafo, por exemplo. A representação por diagramas geralmente torna mais fácil a assimilação de dados relevantes e a percepção de relações e dependências. 
3. Formule um problema equivalente.

Nem sempre um problema pode ser resolvido diretamente, seja porque os cálculos tornam-se muito complicados ou porque o problema simplesmente não possui casos especiais que lancem qualquer visão sobre uma possível resolução. Nesse caso, é recomendável tentar reformular o problema para que tenha uma forma mais simples, mas ainda equivalente ao problema original e, para isso, apela-se para a imaginação e criatividade de cada um. Algumas dessas técnicas envolvem manipulações algébricas ou trigonométricas, mudança de variáveis e reinterpretação do problema em outros contextos (álgebra, geometria, combinatória etc).

4. Modifique o problema.

No decorrer do trabalho para a resolução do problema A, podemos ser levados a considerar o problema B. De um modo característico, essa mudança de problemas ocorre pelo uso das frases "É suficiente mostrar que ...", ou "Podemos assumir que ...", ou ainda "Sem perda de generalidade ...".

5. Escolha uma notação efetiva.

Um dos primeiros passos ao se trabalhar em um problema de Matemática é traduzir esse problema. Inicialmente, todos os conceitos-chave devem ser identificados e rotulados. As redundâncias na notação podem ser eliminadas à medida que novas relações são descobertas.

6. Explore as simetrias.

A presença de simetria em um problema normalmente significa a redução de trabalho na resolução do problema. Por exemplo, ao realizarmos o produto $(a+b+c)\left(a^{2}+b^{2}+c^{2}-a b-a c-b c\right)$ vemos que ambas as parcelas são simétricas com relação aos símbolos $a, b$ e $c$, ou seja, se realizarmos uma permutação qualquer entre os símbolos $a, b$ e $c$, a expressão permanece inalterada. Assim é de se esperar que, se o termo $a^{3}$ aparece no produto, os fatores $b^{3}, c^{3}$ também apareçam. Se $a^{2} b$ aparecer, os termos $a^{2} c, a b^{2}, a c^{2}, b^{2} c, b c^{2}$ também deverão aparecer com os mesmos coeficientes.

7. Divida em casos.

Frequentemente pode acontecer de um problema ser dividido em um pequeno número de subproblemas. Isso é especialmente verdade quando o problema contém um quantificador universal ('para todo x ...'). Por exemplo, na prova de uma proposição da forma 'para todos os inteiros...', podemos provar separadamente os casos de inteiros pares e ímpares. De modo similar, um teorema sobre triângulos pode ser demonstrado separando os casos em que ele é agudo, retângulo ou obtuso. Às vezes, os subproblemas podem ser organizados hierarquicamente em submetas de tal forma que a solução possa ser realizada em sucessivos estágios.

8. Raciocine de trás para frente.

Raciocinar de trás para frente significa assumir a conclusão e então deduzir fatos dessa conclusão até aparecer algo que possa ser facilmente demonstrado. Depois de chegar às hipóteses ou a algo conhecido, revertemos os passos do argumento e seguimos na ordem original (começando das hipóteses e terminando na afirmação do problema).

9. Argumente por contradição.

Argumentar por contradição significa assumir que a conclusão é falsa e então derivar raciocínios até se deparar com uma afirmação que contradiz a hipótese (forma contrapositiva), ou algo que sabemos ser verdadeiro (reductio ad absurdum ou redução ao absurdo). Dessa forma, por exemplo, para demonstrar que raiz quadrada de 2 é irracional, podemos assumir que ela é 
racional e derivar daí um absurdo. Esse método é frequentemente apropriado quando a conclusão é facilmente negável, quando a hipótese fornece poucas informações para manipulação ou quando existe uma escassez de ideias sobre como proceder na solução do problema.

10. Procure por paridade.

Muitos problemas podem ser resolvidos observando a invariância da paridade e imparidade dos números inteiros que aparecem nas informações do problema.

11. Considere os casos extremos.

Nos estágios iniciais da exploração do problema, frequentemente é útil considerar as consequências da variação dos parâmetros entre casos extremos. Isso ocorre frequentemente com o uso das frases "Na pior (melhor) das hipóteses ..."e "No pior (melhor) dos casos ...".

12. Generalize.

Isto pode parecer paradoxal, mas é frequente o caso em que um problema pode ser simplificado e tornado mais tratável e inteligível depois de generalizado. Esse fato é bem apreciado por matemáticos. Com efeito, generalizações são características básicas da Matemática. Uma abordagem mais geral fornece uma perspectiva mais clara, elimina informações não essenciais e providencia um arsenal inteiro de novas técnicas.

O uso de estratégias para resoluções de problemas de Matemática é foco de muitas pesquisas, como por exemplo, [1], [3], [4], [5], [7], [8], [9], [14] e [15]. Neste artigo construímos, inspirados nessas pesquisas, resoluções de alguns problemas de Matemática, os quais são apresentados na Educação Básica, envolvendo álgebra, geometria e trigonometria. Para resolver os problemas propostos, utilizamos predominantemente a segunda estratégia listada por Larson, isto é, "trace uma figura", bem como a sexta estratégia "explore as simetrias"e a sétima estratégia "divida em casos". De fato, a resolução visual de cada problema é dada por uma sequência de figuras.

\section{Problemas de matemática e suas resoluções visuais}

Nesta seção apresentamos resoluções de alguns problemas de Matemática, que geralmente são contemplados na Educação Básica.

A primeira resolução visual que apresentamos refere-se ao Teorema de Pitágoras. Nesse caso, consideramos um triângulo retângulo de lados $a, b$ e $c$ (Figura 1). Assim, a Figura 1 ilustra a sequência de passos necessários para obter a resolução do problema proposto, isto é,

$$
c^{2}=a^{2}+b^{2} .
$$



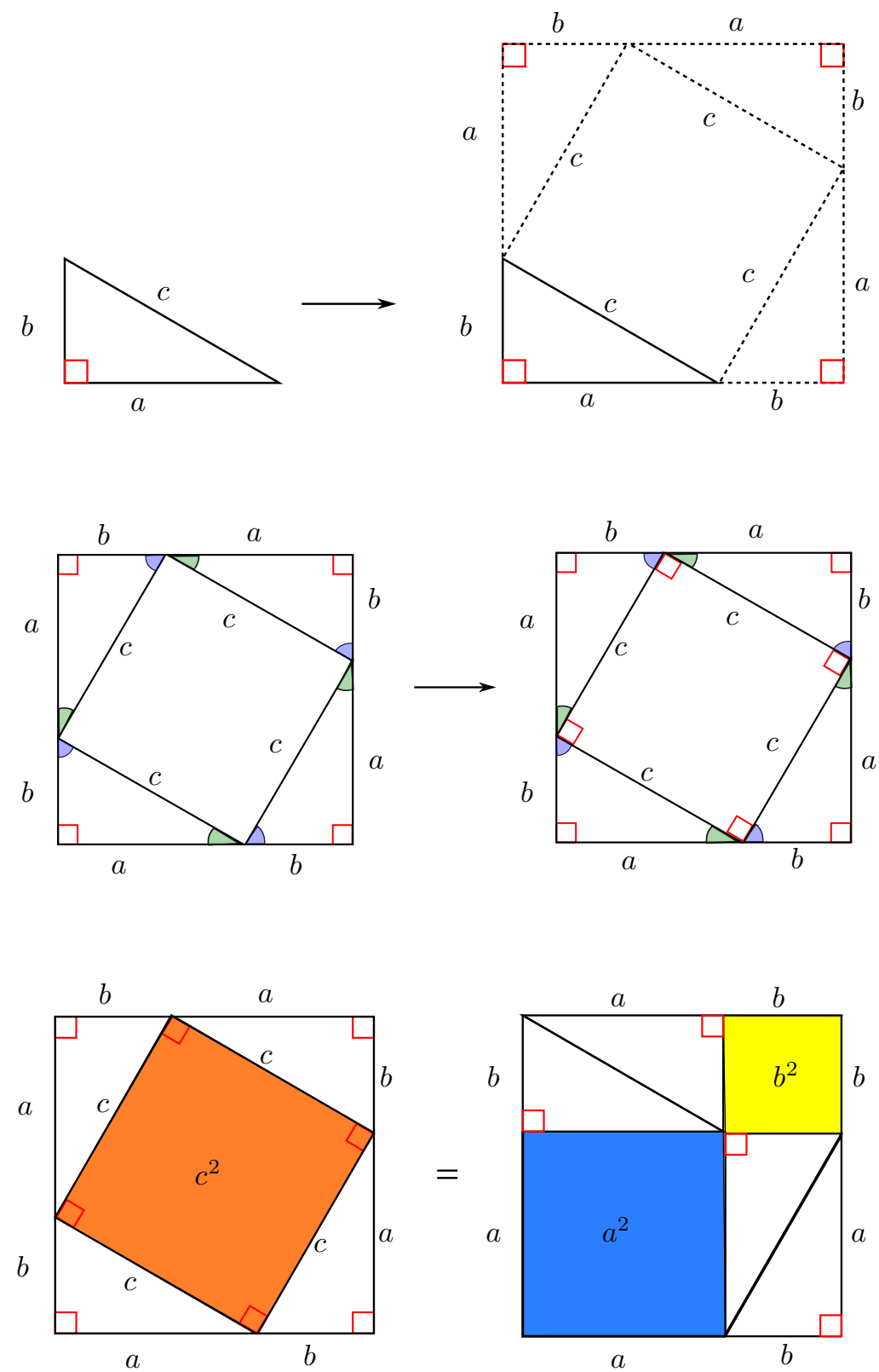

Figura 1: Resolução visual para o Teorema de Pitágoras Fonte: Autoria própria

Considerando $n$ um número natural, a Figura 2 ilustra como é possível mostrar que

$$
1+3+5+\ldots+(2 n-1)=n^{2} .
$$



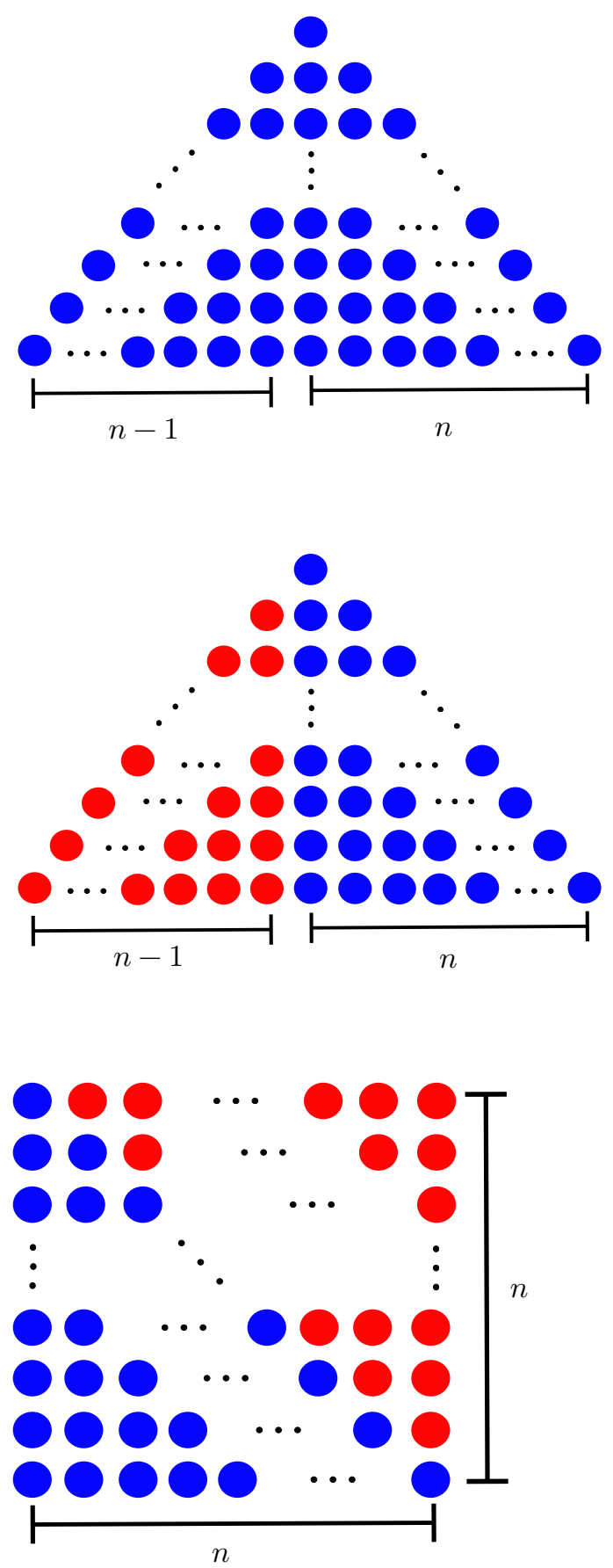

Figura 2: Resolução visual para a soma dos $n$ primeiros números ímpares Fonte: Autoria própria 
O terceiro problema proposto refere-se ao completamento de quadrados, ou seja,

$$
x^{2}+a x=\left(x+\frac{a}{2}\right)^{2}-\left(\frac{a}{2}\right)^{2},
$$

onde $x>0$ e $a>0$. Mostramos (Figura 3) como tal algebrismo torna-se viável ao utilizar somente figuras.
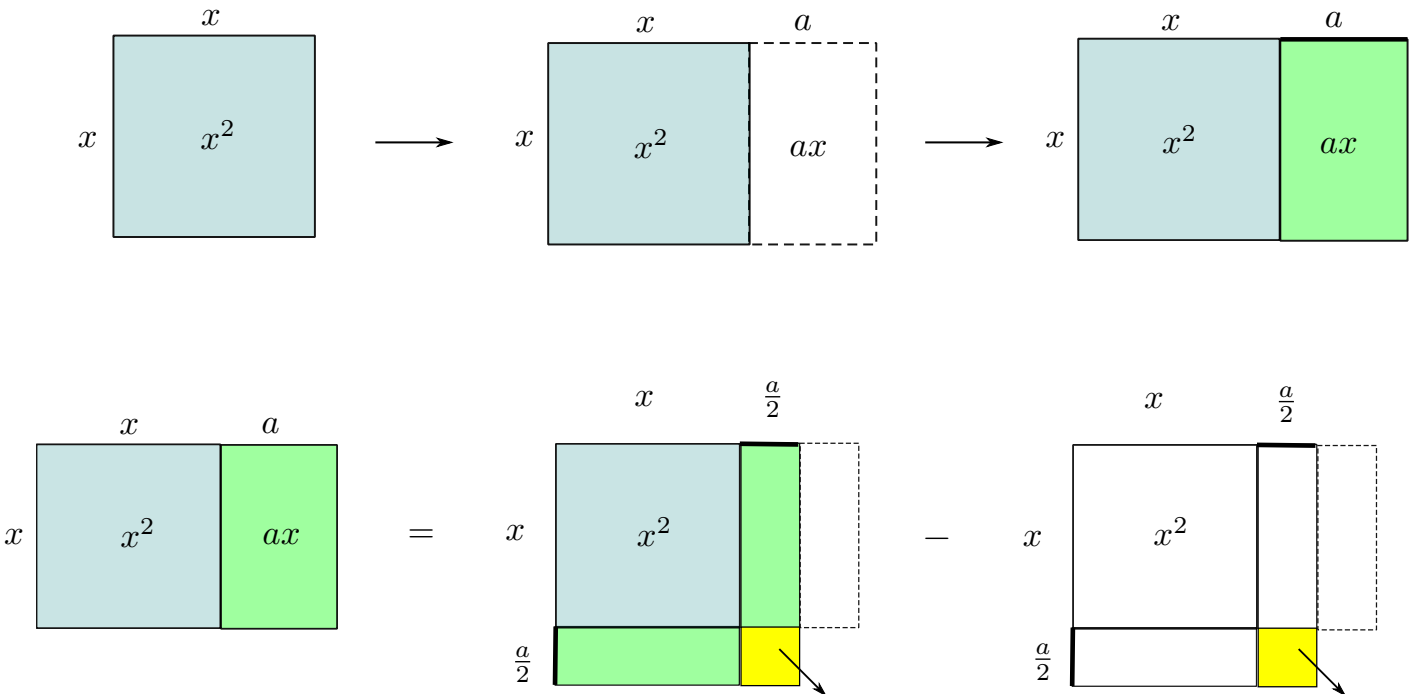

$\left(\frac{a}{2}\right)^{2}$
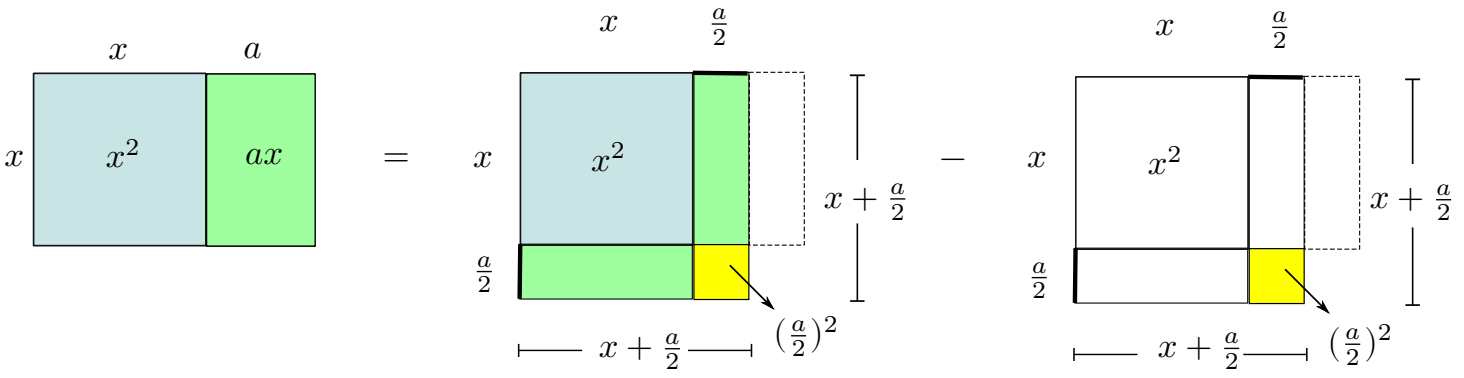

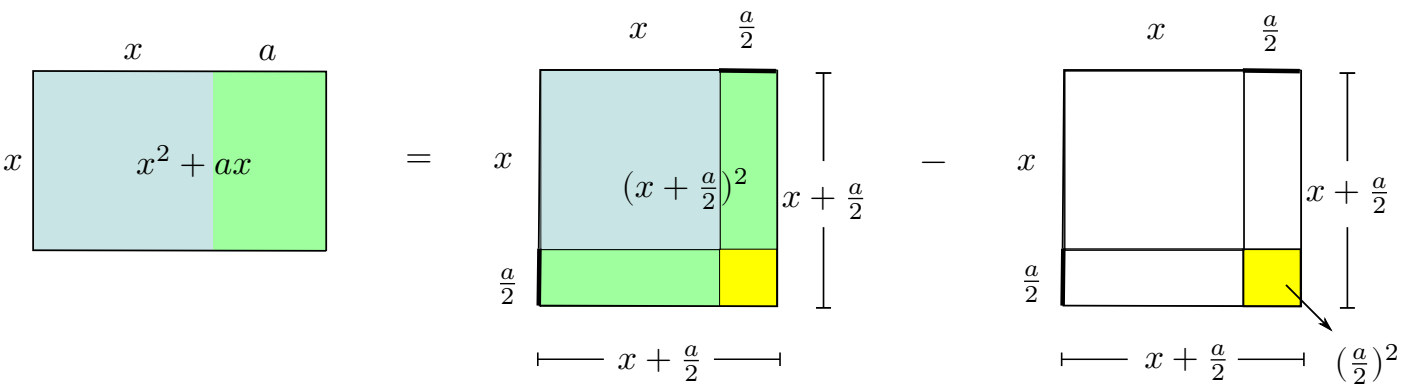

Figura 3: Resolução visual para o completamento de quadrados Fonte: Autoria própria

A próxima resolução visual que apresentamos concerne a desigualdade entre média aritmética e geométrica, isto é,

$$
\frac{a+b}{2} \geq \sqrt{a b},
$$

onde $a>0, b>0$ e $a<b$. Ilustramos a resolução desta desigualdade com uma sequência de figuras (Figura 4).
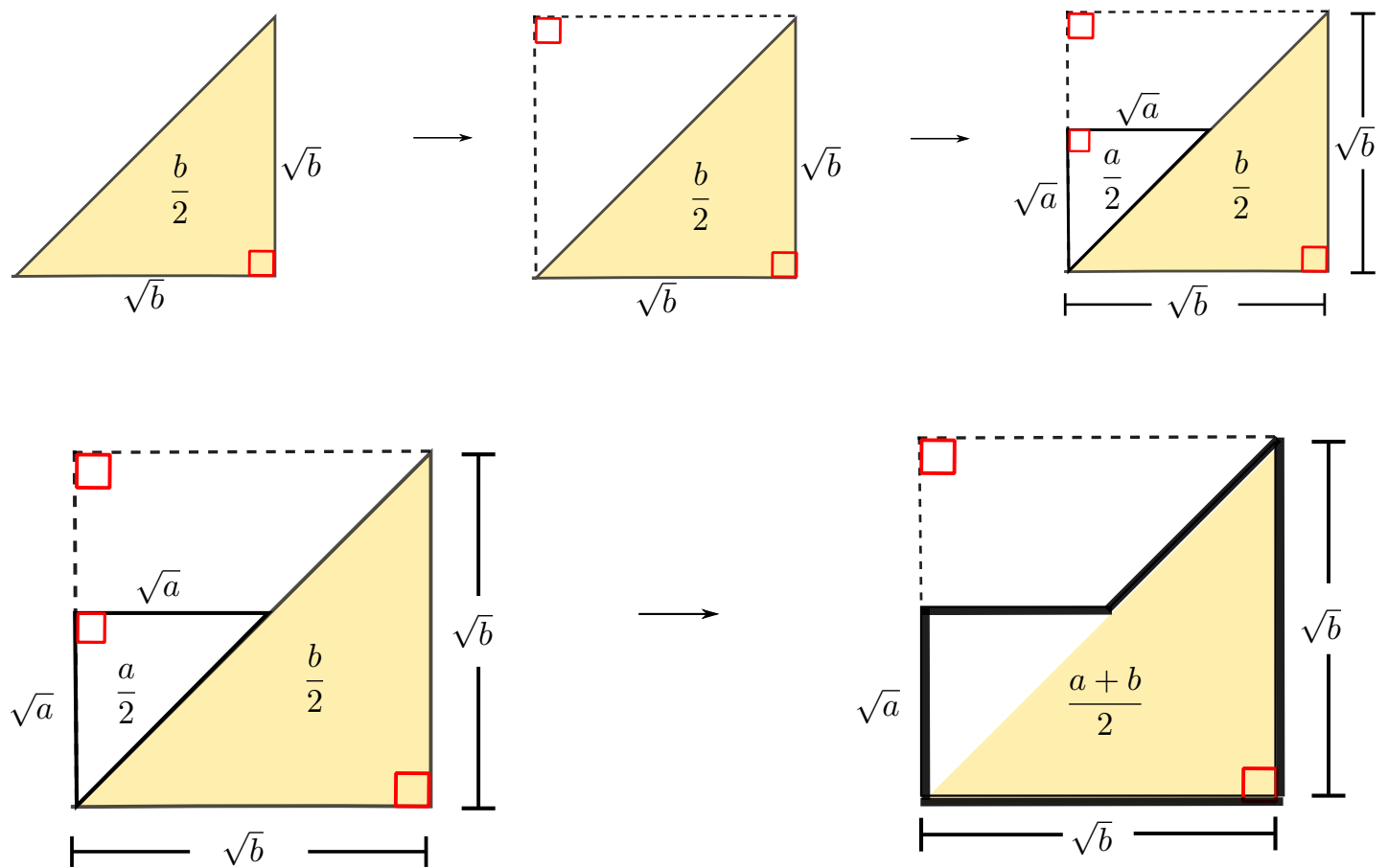

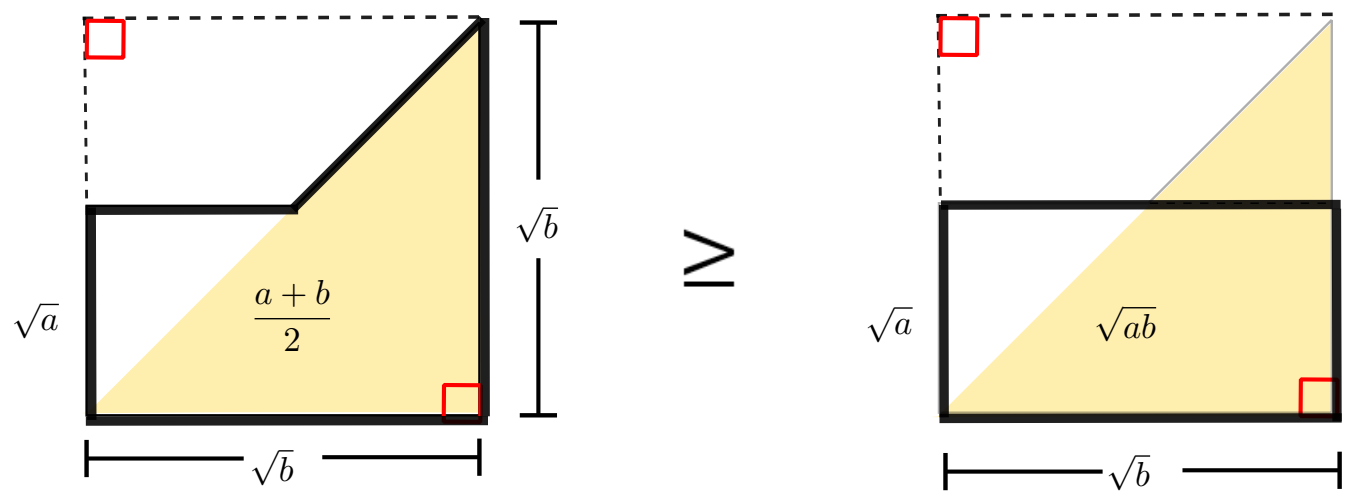

Figura 4: Resolução visual para a desigualdade entre média aritmética e geométrica Fonte: Autoria própria

Dados dois ângulos $\alpha$ e $\beta$ tais que $0<\alpha-\beta<\frac{\pi}{2}$, apresentamos na Figura 5 a resolução visual para o seno da diferença de dois ângulos, isto é,

$$
\operatorname{sen}(\alpha-\beta)=\operatorname{sen} \alpha \cos \beta-\operatorname{sen} \beta \cos \alpha \text {. }
$$
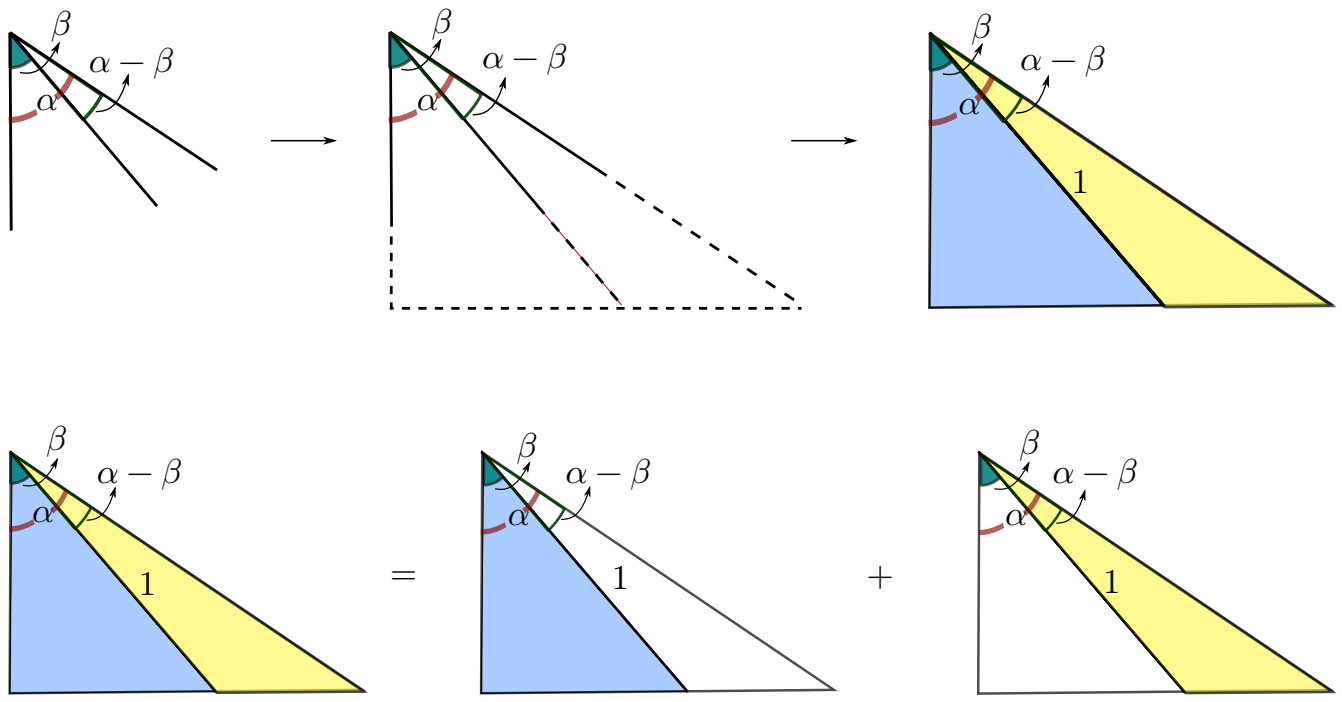


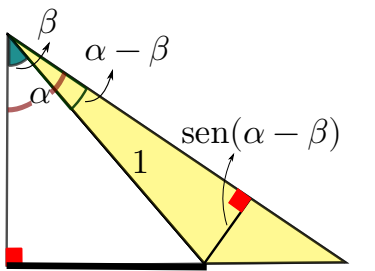

$\operatorname{sen} \beta$

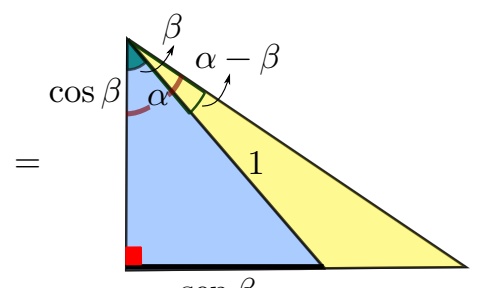

$\operatorname{sen} \beta$
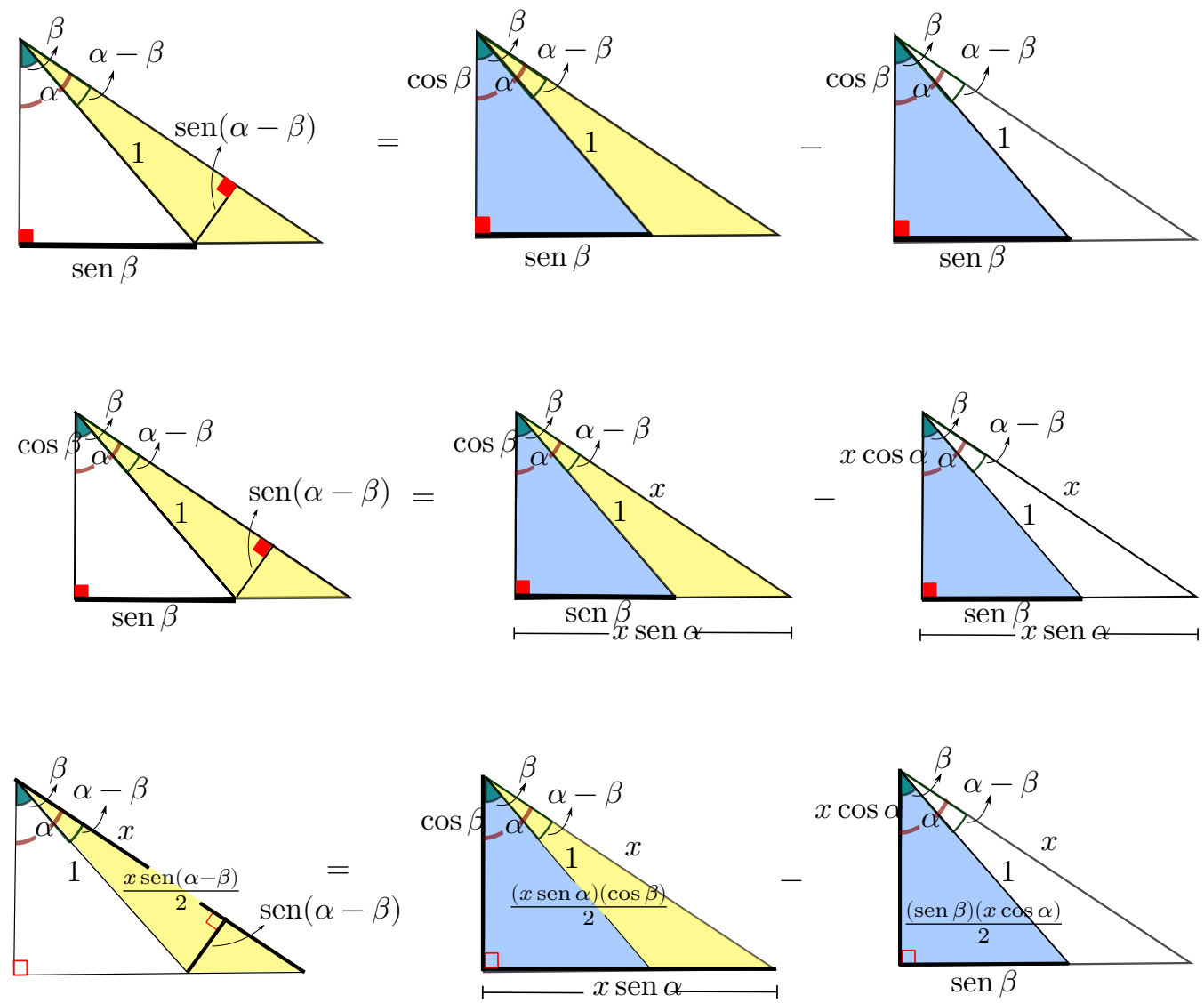

Figura 5: Resolução visual para o seno da diferença de dois ângulos

Fonte: Autoria própria

Uma interessante série geométrica é dada por

$$
\frac{1}{4}+\left(\frac{1}{4}\right)^{2}+\left(\frac{1}{4}\right)^{3}+\ldots=\frac{1}{3}
$$

Usando figuras triangulares, exibimos uma resolução visual para esse problema, ver Figura 6.
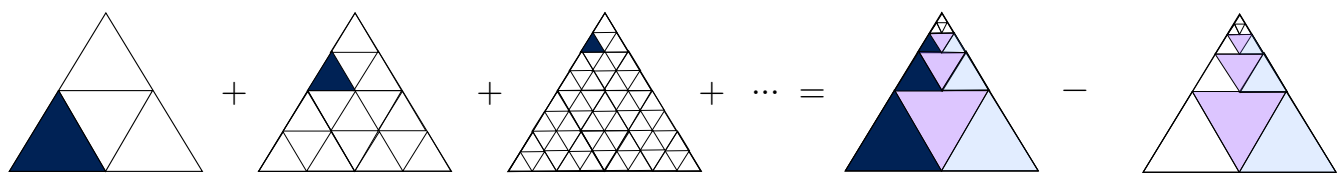

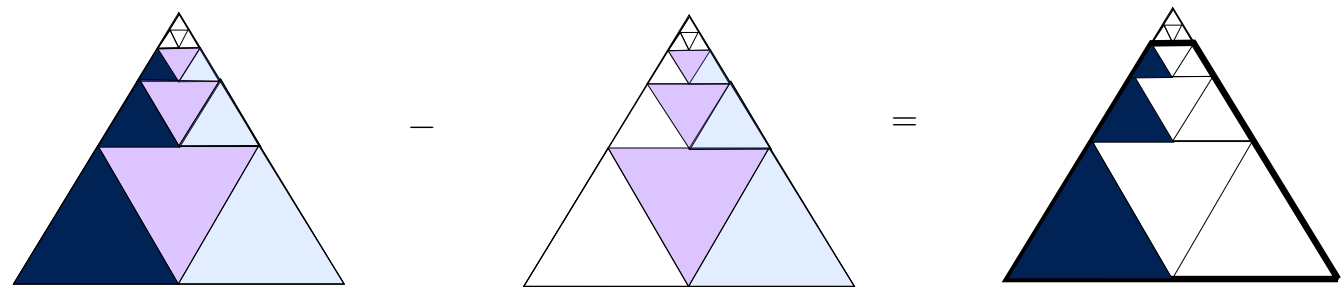

Figura 6: Resolução visual para a série geométrica

Fonte: Autoria própria

Sejam $\alpha$ e $\beta$ dois ângulos tais que $0<\alpha, \beta<\frac{\pi}{2}$. Apresentamos na Figura 7 a resolução visual para a tangente da soma de dois ângulos, isto é,

$$
\tan (\alpha+\beta)=\frac{\tan \alpha+\tan \beta}{1-\tan \alpha \tan \beta} .
$$
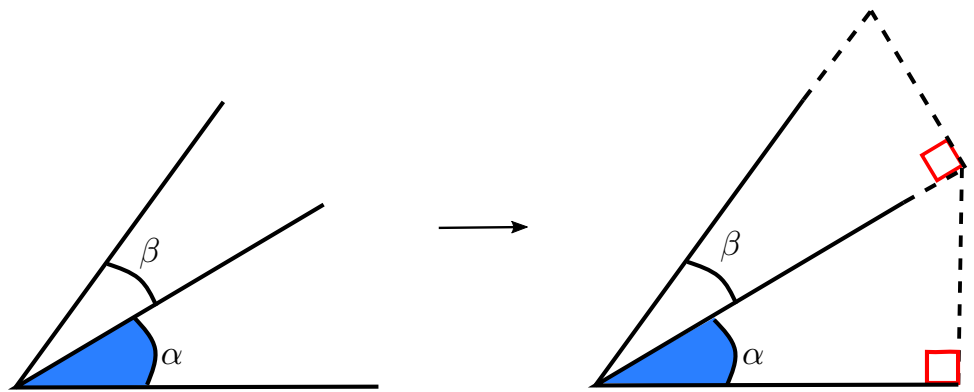

1

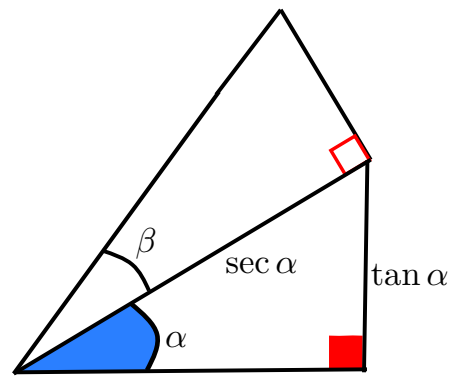

1

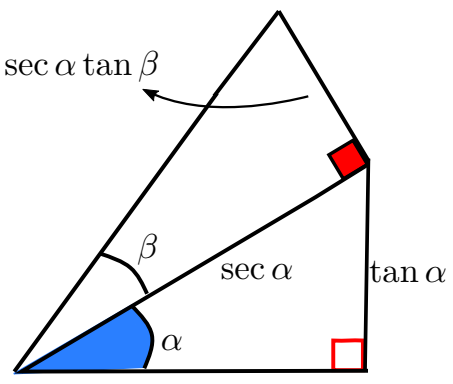

1 
$\tan \alpha \tan \beta$

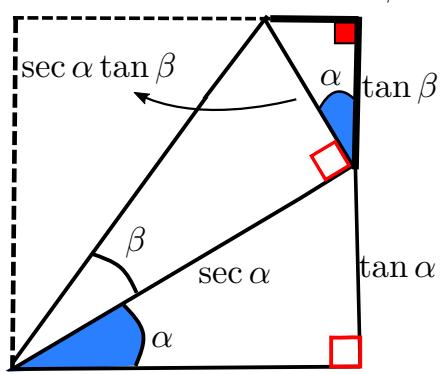

1

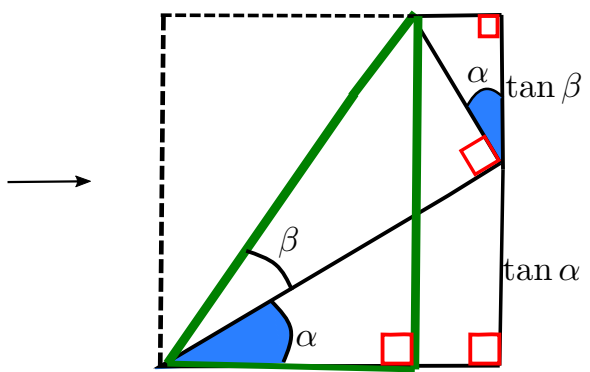

$1-\tan \alpha \tan \beta$

Figura 7: Resolução visual para a tangente da soma de dois ângulos Fonte: Autoria própria

Considerando um ângulo $\alpha$ tal que $0<\alpha<\frac{\pi}{4}$, mostramos uma resolução visual, ver Figura 8 , para o cosseno do arco duplo, isto é,

$$
\cos 2 \alpha=1-2 \operatorname{sen}^{2} \alpha .
$$
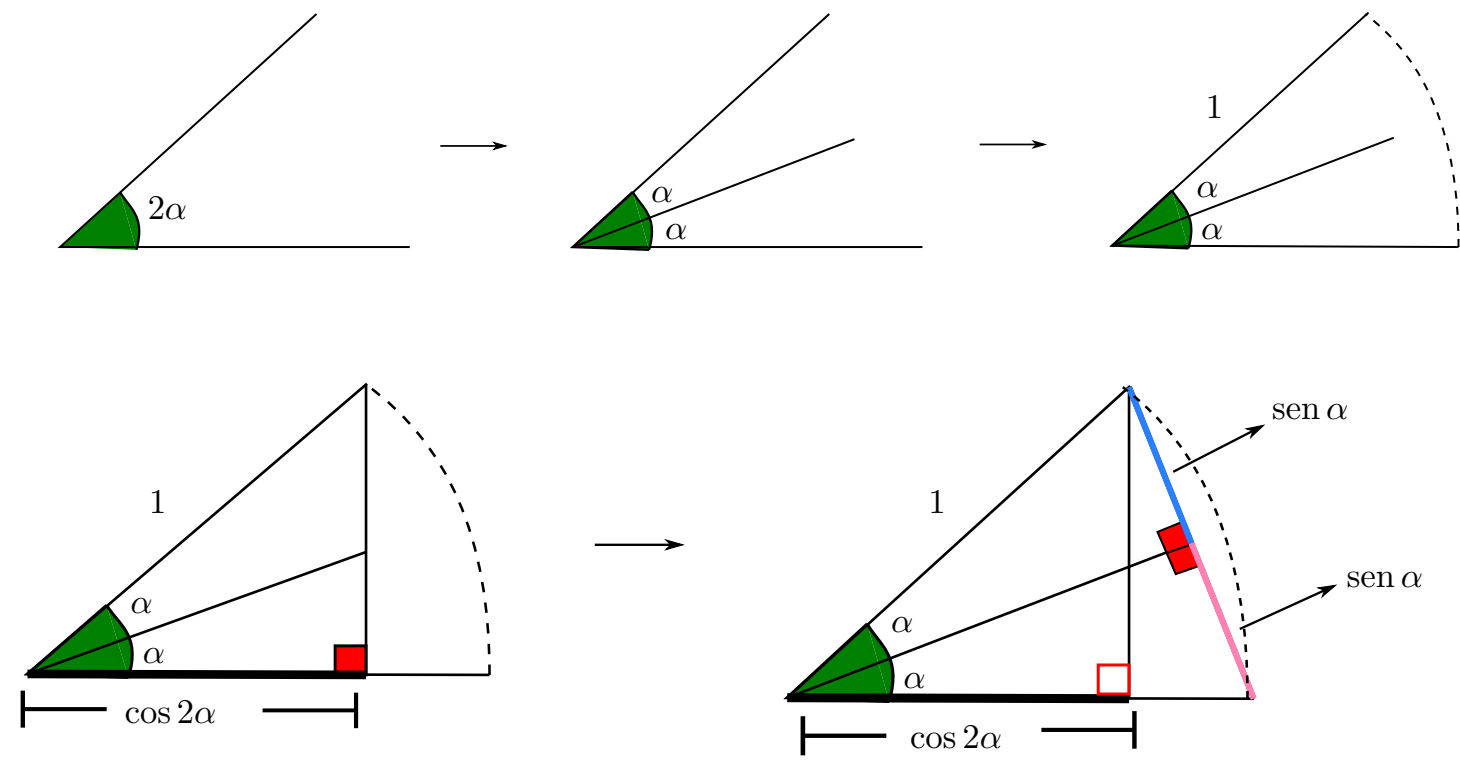

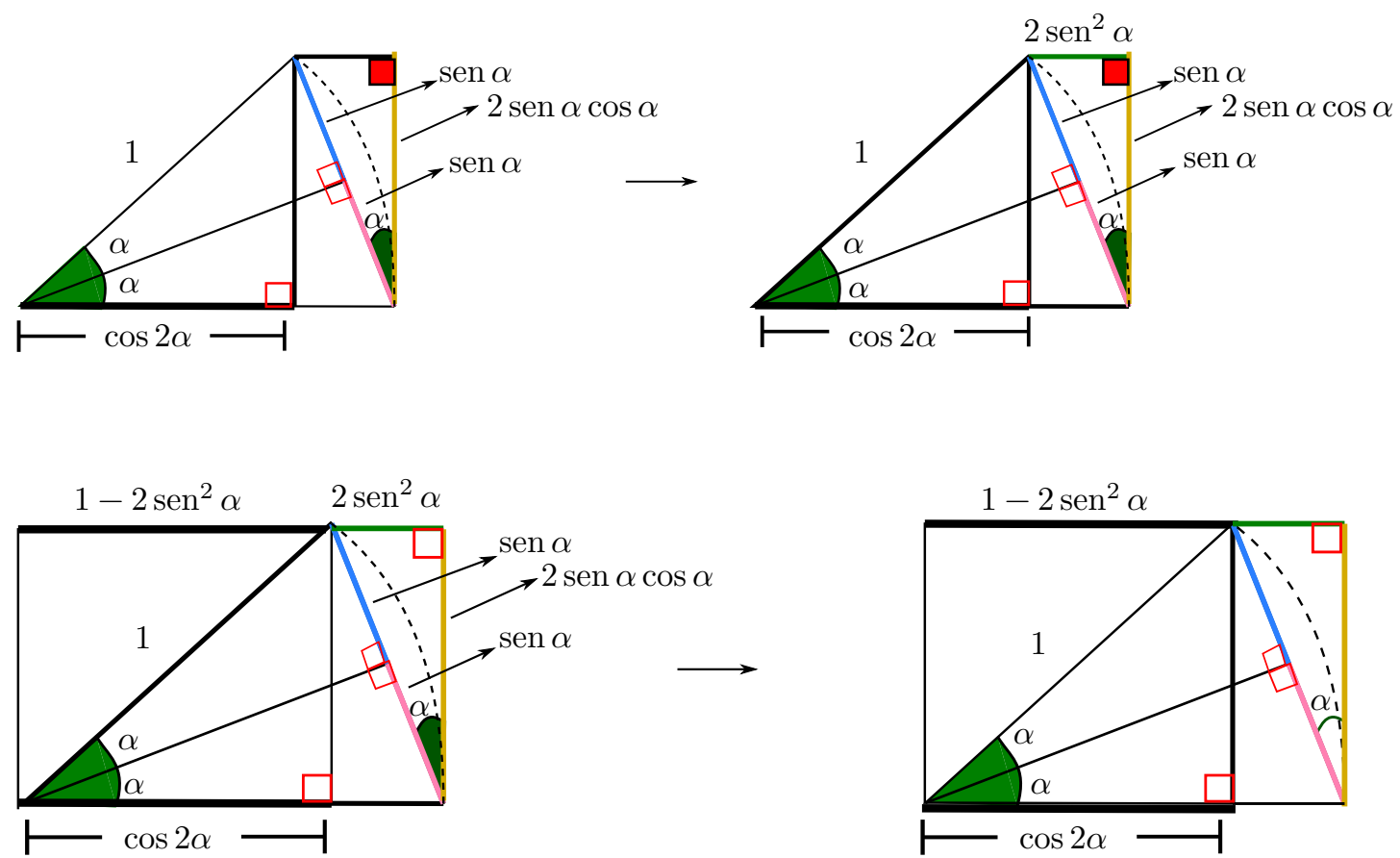

Figura 8: Resolução visual para o cosseno do arco duplo

Fonte: Autoria própria

Dado um ângulo $\beta$ tal que $0<\beta<\frac{\pi}{4}$, expomos na Figura 9 uma resolução visual para o seno do arco duplo, isto é,

$\operatorname{sen} 2 \beta=2 \operatorname{sen} \beta \cos \beta$.
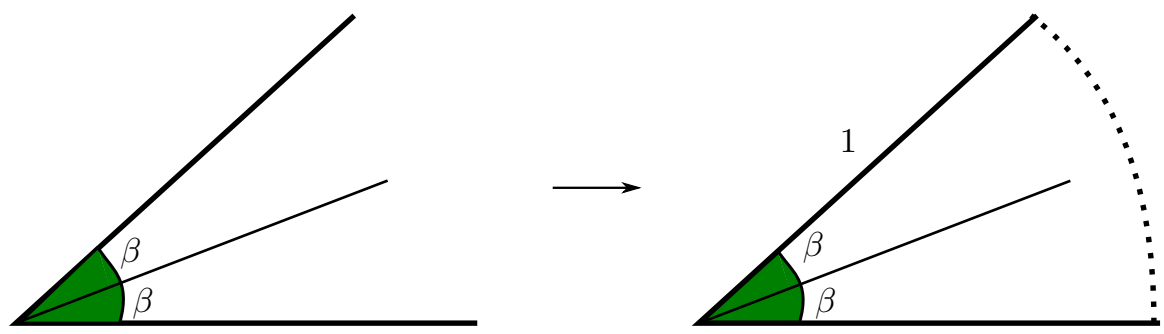

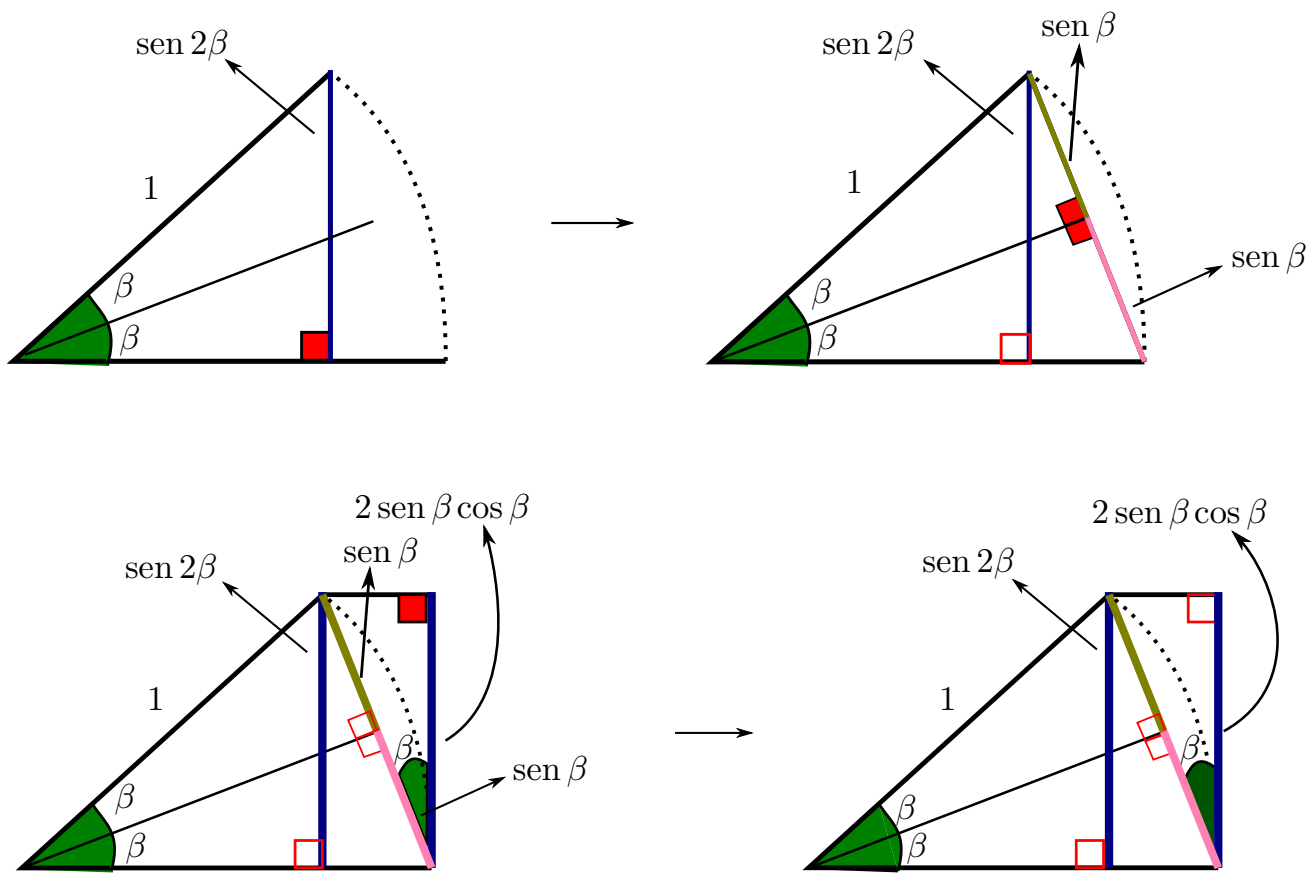

Figura 9: Resolução visual para o seno do arco duplo Fonte: Autoria própria

O décimo problema proposto refere-se à tangente da diferença entre dois ângulos, ou seja,

$$
\tan (\alpha-\beta)=\frac{\tan \alpha-\tan \beta}{1+\tan \alpha \tan \beta}
$$

onde $0<\alpha, \beta<\frac{\pi}{2}$.

Apresentamos a resolução visual deste problema mediante a Figura 10.
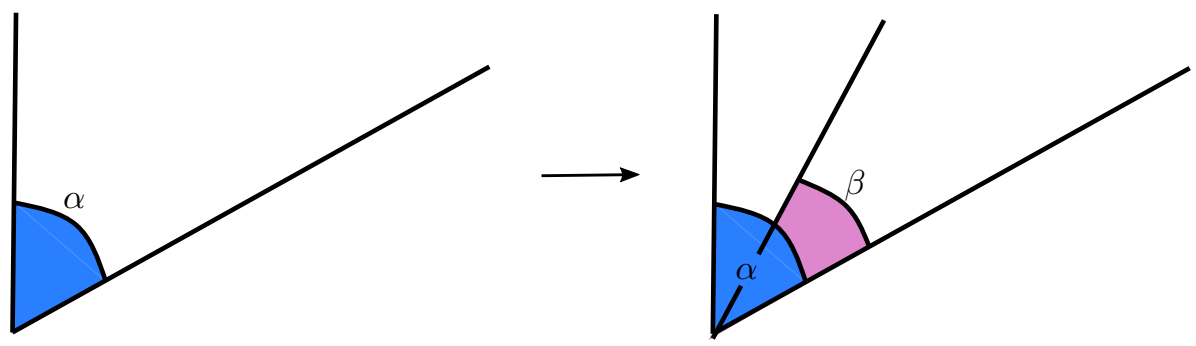

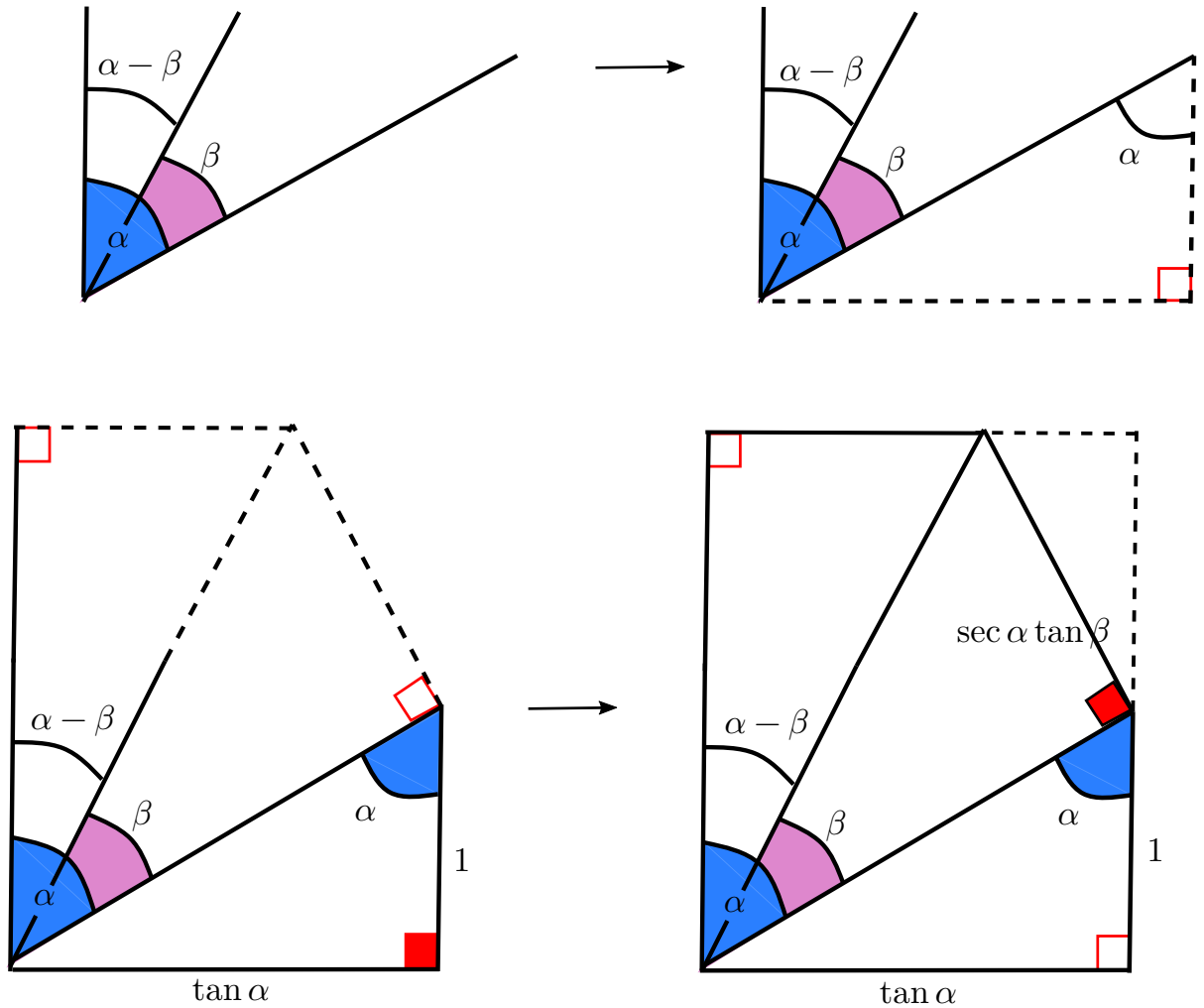

$\tan \beta$
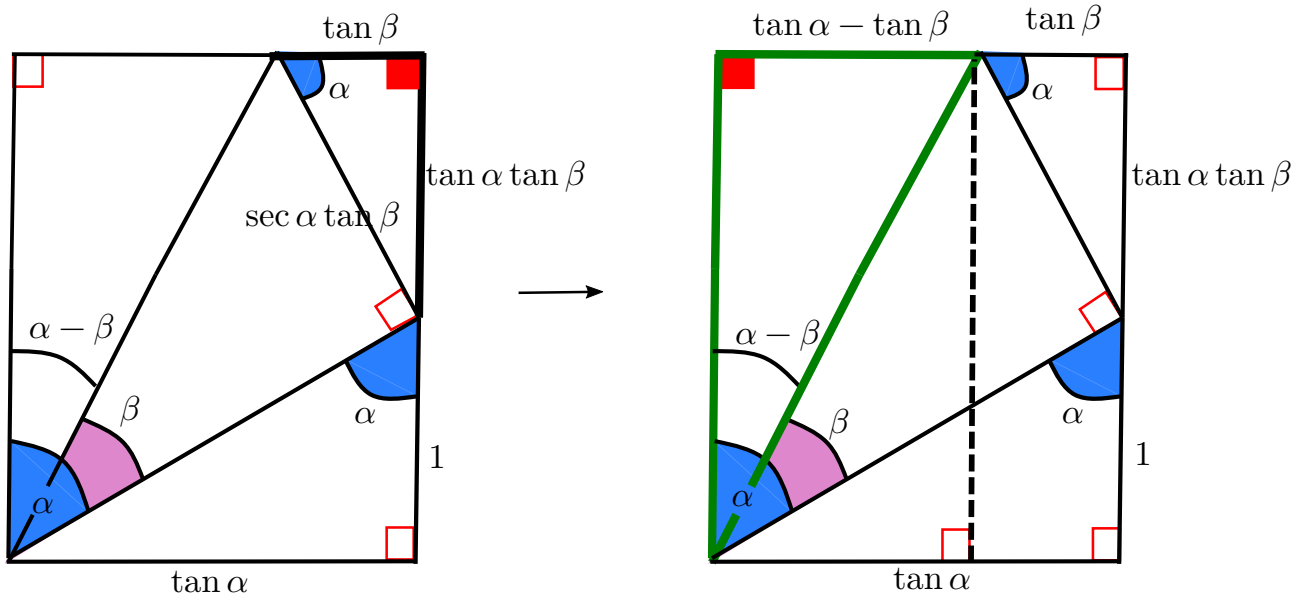

Figura 10: Resolução visual para a tangente da diferença entre dois ângulos Fonte: Autoria própria 
A partir de um segmento que possui medida $a$, ilustramos na Figura 11 uma resolução visual de uma propriedade das proporções, ou seja,

$$
\frac{a+b}{a-b}=\frac{c+d}{c-d},
$$

onde $b>0, c>0, d>0$ e $\frac{a}{b}=\frac{c}{d} \neq 1$.
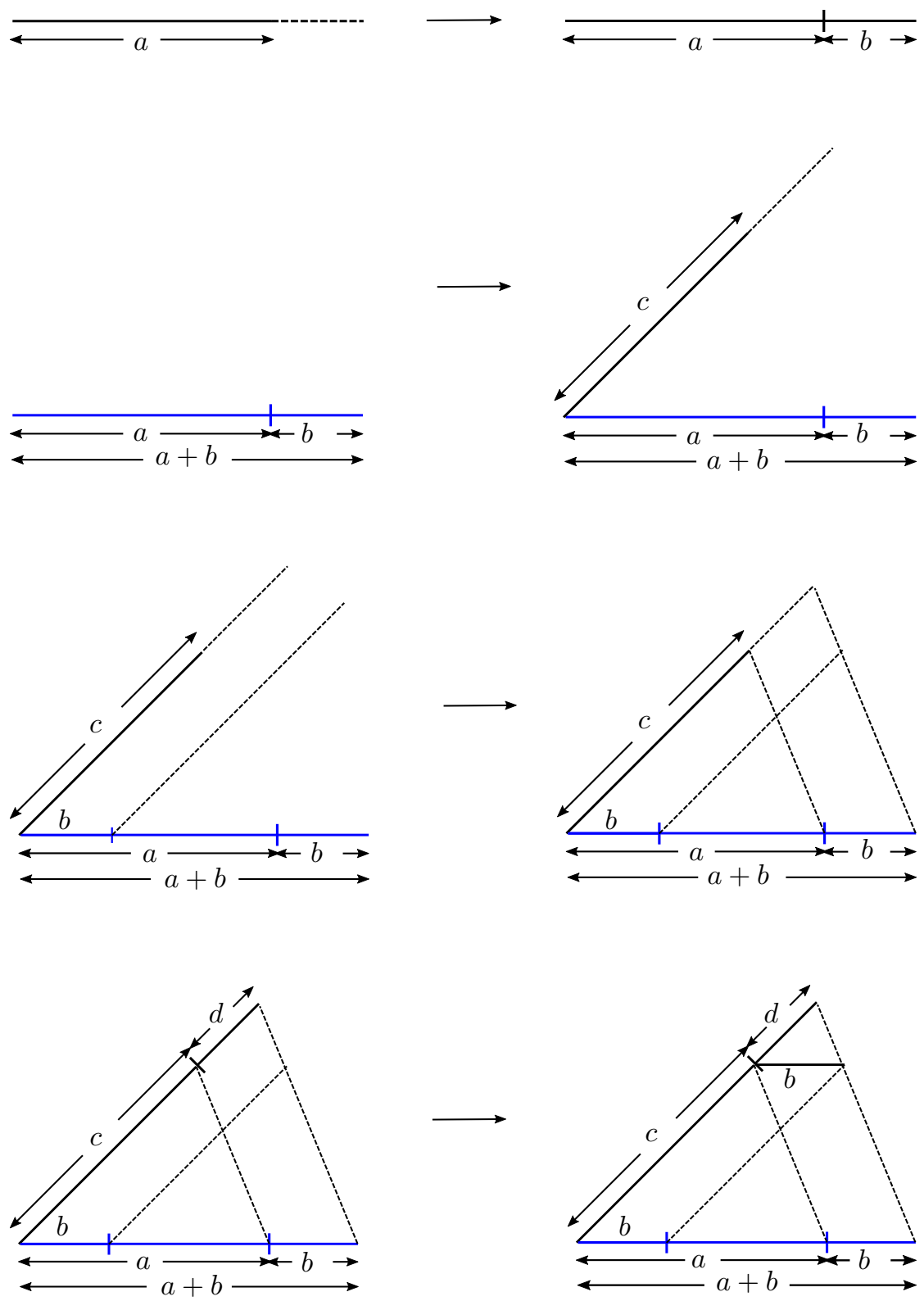

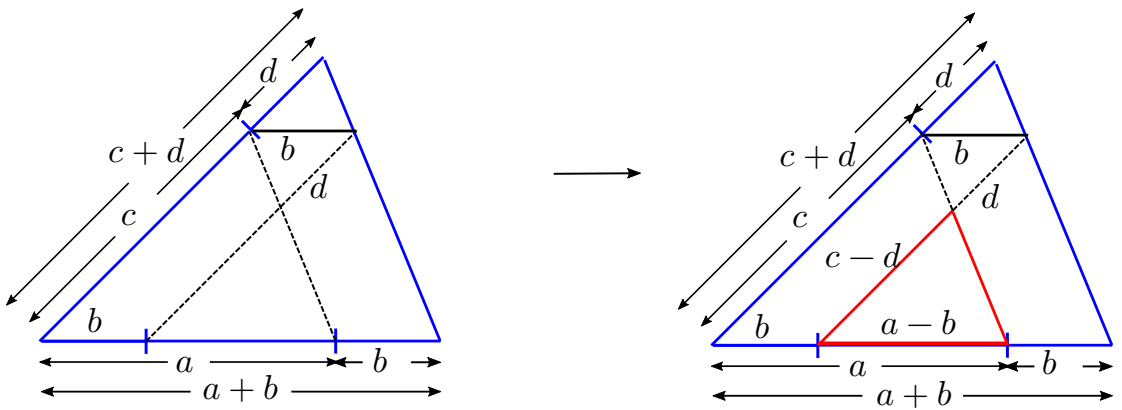

Figura 11: Resolução visual para uma propriedade das proporções Fonte: Autoria própria

A última resolução visual refere-se à lei dos cossenos, isto é,

$$
c^{2}=a^{2}+b^{2}-2 a b \cos \alpha
$$

onde $a, b$ e $c$ são positivos. Nesse caso, consideramos um triângulo de lados $a, b$ e $c$, que possui um ângulo $\alpha$ tal que $0<\alpha<\frac{\pi}{2}$. Assim, na Figura 12 exibimos uma sequência de passos necessários para a resolução desse problema.
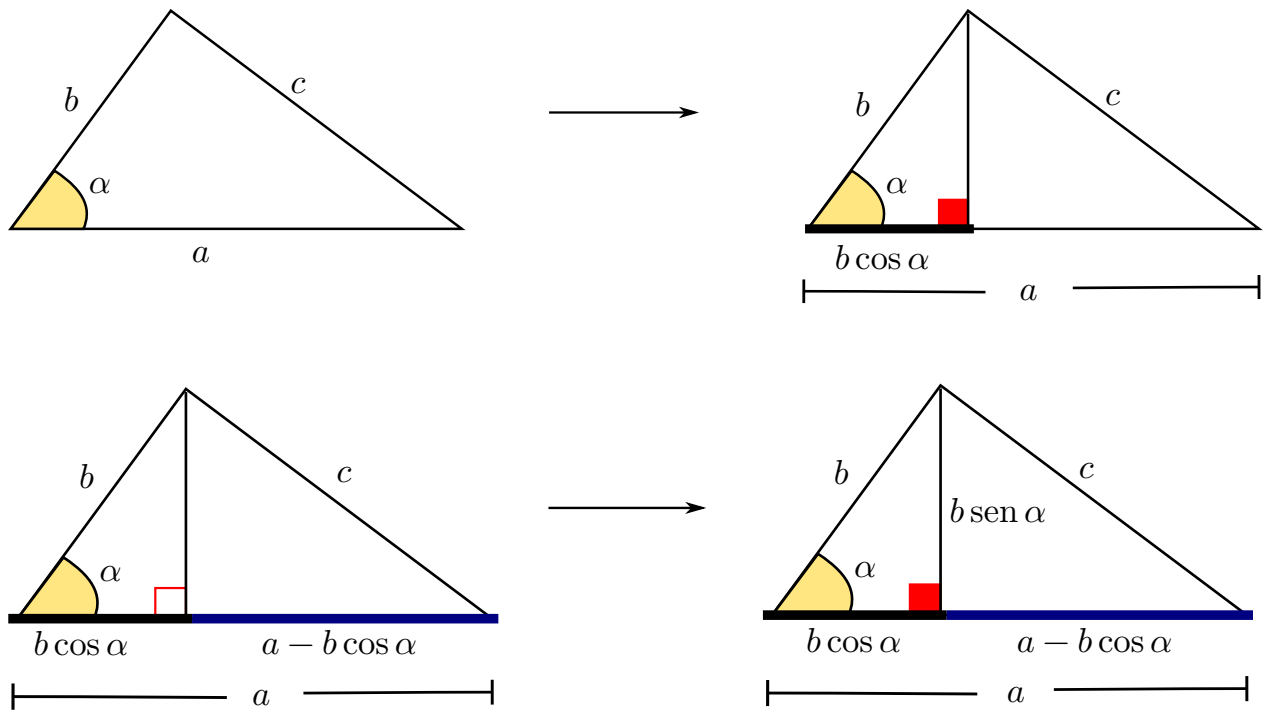

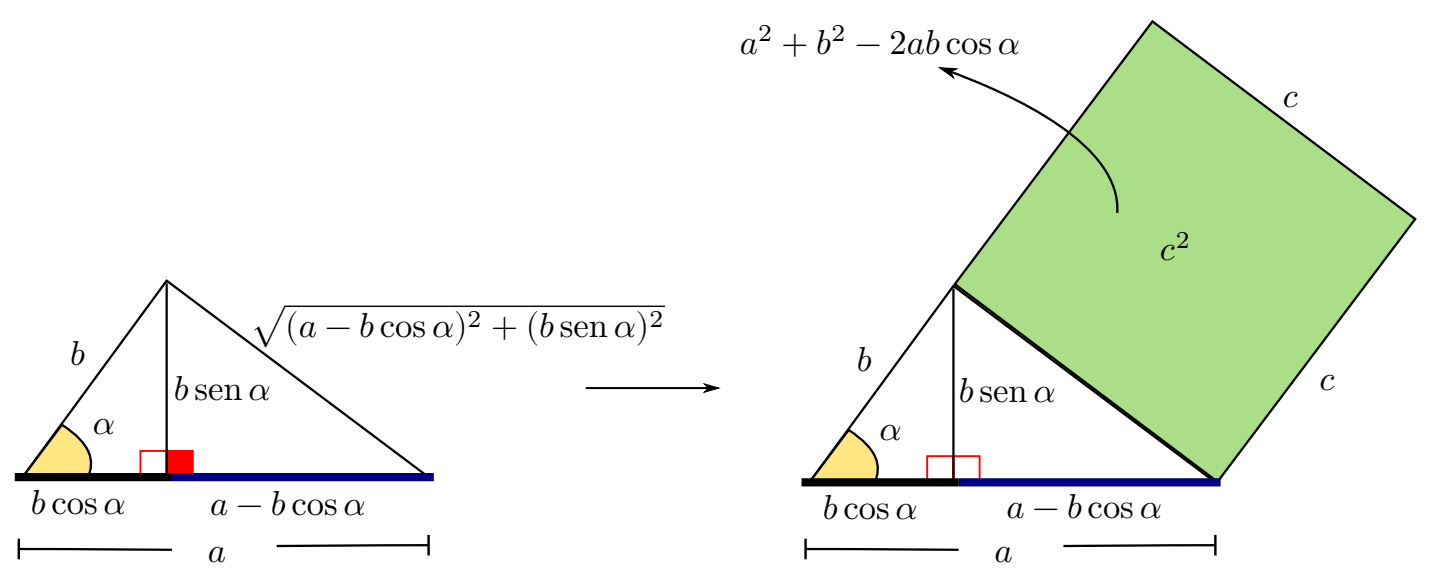

Figura 12: Resolução visual para a lei dos cossenos

Fonte: Autoria própria

\section{Conclusão}

O uso das estratégias listadas por Larson, ver [6], notadamente "trace uma figura", "explore as simetrias"e "divida em casos", mostra fortemente a importância da visualização de cada problema, e, consequente, obtém-se uma maior clareza na busca de sua resolução. De fato, a atitude de visualizar um problema provoca um olhar desafiador de imaginação geométrica, o qual direciona a criatividade para outra forma importante e cristalina de encontrar resoluções de problemas. Destacamos que os problemas apresentados e resolvidos neste artigo são alguns exemplos de problemas de Matemática da Educação Básica. Provavelmente, o professor em sua prática diária, pode tomar esses exemplos como ponto inicial e ampliar o leque de atividades realizadas em sala de aula, criando novas possibilidades de investigação.

\section{Agradecimentos}

Os autores são gratos a Carmen Vieira Mathias e Letícia Rangel pelos comentários e sugestões.

\section{Referências}

[1] Alsina, C; Nelsen, R. B. Math Made Visual. MAA, p. 4, 2006.

[2] Descartes, R. Oeuvres de Descartes. Ch. Adam \& P. Tannery, Paris: Vrin/CNRS, 1964.

[3] Gallant, C. D. Completing the square. Mathematics Magazine, v. 56, n. 2 ,p. 110, 1983.

[4] Kobayashi, Y. Proof Without Words: Componendo et Dividendo, a Theorem on Proportions. The College Mathematics Journal, v. 45, n. 2, p. 115, 2014.

[5] Kung, S. H. Area and difference formulas. Mathematics Magazine, v. 62, n. 5, p. 317, 1989.

[6] Larson, L. C. Problem-Solving Through Problems. Springer, New York, 1983. 
[7] Mabry, R. Proof Without Words: $\frac{1}{4}+\left(\frac{1}{4}\right)^{2}+\left(\frac{1}{4}\right)^{3}+\ldots=\frac{1}{3}$. Mathematics Magazine, v. 72, n. 1, p. $63,1999$.

[8] Nelsen, R. B. One figure, six identities. The College Math. Journal, v. 31, n. 2, p. 145-146, 2000.

[9] Polya, G. A arte de resolver problemas: um novo aspecto do método matemático. Interciência, Rio de Janeiro, 1995.

[10] Polya, G. Mathematics and Plausible Reasoning: Patterns of Plausible Inference. Princeton University Press, v. 2, Princeton, 1968.

[11] Polya, G. Mathematics and Plausible Reasoning: Induction and Analogy in Mathematics. Princeton University Press, v. 1, Princeton, 1990.

[12] Schoenfeld, A. H. Mathematical Problem Solving. Academic Press, New York, 1985.

[13] Schoenfeld, A. H. Pólya, Problem Solving, and Education. Mathematics Magazine, v. 60, p. 283-291, 1987.

[14] Sipka, T. A. The law of cosines. Mathematics Magazine, v. 61, n. 4, p. 259, 1988.

[15] Unal, H. Double sum for sine and cosine. The College Math. Journal, v. 41, n. 5, p. 392, 2010.

Hilário Alencar Universidade Federal de Alagoas $<$ hilario@mat.ufal.br>

Larissa Cândido

Universidade Federal de Alagoas $<$ larikarollynne95@gmail.com>

Milena Farias

Escola Estadual Dra. Eunice de Lemos Campos $<$ milagleice7@gmail.com>

Recebido: 19/02/2019 